\title{
Physiotherapy programme in unspecific haemorrhagic brain stroke: A case study of a young adult
}

\author{
Laura Piejko ${ }^{1}$, Aleksandra Stojek ${ }^{\mathbf{1}}$ \\ 1Department of Physiotherapy in Internal Diseases, Institute of Physiotherapy and Health Sciences, \\ The Jerzy Kukuczka Academy of Physical Education, Katowice, Poland \\ Correspondence to: Laura Piejko, I.piejko@awf.katowice.pl \\ DOI: https://doi.org/10.5114/phr.2021.109029
}

Received: 19.02.2021 Reviewed: 19.03.2021 Accepted: 19.03.2021

\begin{abstract}
Background: Stroke in young people can leave them with a disability before their most productive years due to a lack of awareness in the young adult population. Rehabilitation of young stroke patients is often associated with a variety of social problems.
\end{abstract}

Aims: To present a case report of the rehabilitation of a 31-year-old patient with uncommon symptoms hospitalised due to haemorrhagic stroke in the left middle cerebral artery (MCA) territory.

Case report: This article presents the case of a 31-year-old woman with uncommon neurological symptoms. A head CT scan revealed a haemorrhagic area in the left MCA territory. The physical examination showed a deterioration in general functioning and upper quadrant hemianopia but no signs of focal central nervous system (CNS) damage and gait problems. The patient followed the doctors' recommendations to exercise under the supervision of a physiotherapist, rest and try not to strain too much. Functional ability was assessed three times: 8 days after hospital admission (23 days from the stroke), 6 months and 1 year after the hospital stay. The Barthel Index
(BI), Berg Balance Scale (BBS) and Tandem Pivot Test (TPT) were performed. The patient case report was given BI scores of 70, 100 and 100 points, BBS scores of 31,47 and 55 points and TPT scores of 3, 5 and 5 points at eight days, six months and one year after the hospital stay, respectively.

Summary: In the case report, the patient's head CT scan revealed a haemorrhage in an area in the left MCA territory. This phenomenon is prognostically bad if it occurs up to six hours after the stroke incident. In this case, almost two weeks passed from the first uncommon stroke symptoms to the proper medical treatment. Physiotherapy exercise programmes provide a chance for proper medical and rehabilitation treatment and faster recovery for patients.

\section{Key words}

hemorrhagic stroke, middle cerebral artery, young patient, physiotherapy 


\section{Introduction}

Stroke is the third most common cause of death after cardiac disease and cancer [1]. Strokes occur primarily in the elderly, although $25 \%$ of strokes are observed in people under 55 years of age [2] and about $15 \%$ in young adults and adolescents [3]. The leading causes of stroke are hypertension, vascular malformations, alcoholism, smoking, low blood cholesterol, drugs, old age, obesity and venous thrombosis [4]. Chronic diseases, such as diabetes, atherosclerosis, blood clotting disorders, cancer and injuries are also considered potential risk factors for stroke [5].

The main symptoms of central nervous system (CNS) damage are hemiplegia or paresis, aphasia, sensory, visual and balance disturbances, dizziness and headaches accompanied by nausea and vomiting. Double vision, dysphagia and, in severe cases, unconsciousness also occur. Cognitive disorders (disorientation in space-time, not recognising famous people, memory impairment) and difficulties in activity daily living (ADL), such as getting dressed and having meals, are also observed [6]. These symptoms are progressive [7].

Stroke in the young can lead to disability before their most productive years [3]. To date, there is poor awareness of and limited efforts to educate medical staff and patients about the severity of stroke in the young adolescent population. Early diagnosis remains challenging because of the lack of awareness and the relative infrequency of stroke compared with stroke mimics [8]. Moreover, the causes of stroke in young people are relatively uncommon, resulting in uncertainties in diagnostic evaluation and case management [9-11].

\section{Aims}

This study aimed to present a case report of the rehabilitation of a 31-year-old woman with uncommon symptoms due to haemorrhagic stroke in the left middle cerebral artery (MCA) territory.

\section{Case report}

This article presents the case of a 31-year-old woman with uncommon neurological symptoms whose CT scan of the head revealed a haemorrhagic area in the left MCA territory with a visible swelling around the focal area with a cross-section of $52 \times 43$ (Fig. 1).
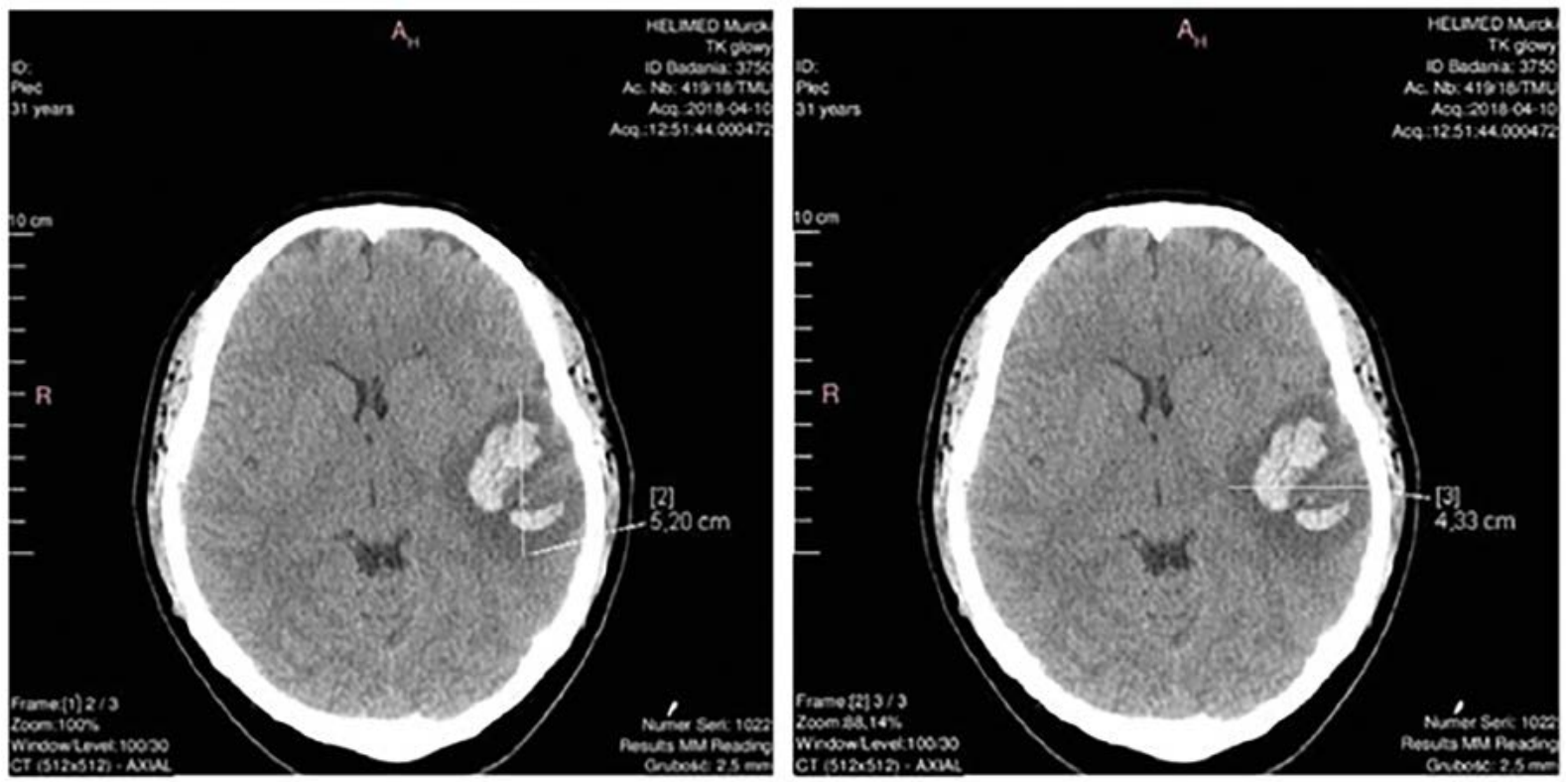

Figure 1. CT scan of the head revealed a haemorrhagic area in the left MCA. 
The patient complained of a gradually increasing toothache radiating to the left ear and left temporal area. Later, an episode of numbness in the left half of the body for a few seconds, general weakness, and an increase in systolic pressure up to $170 \mathrm{~mm} \mathrm{Hg}$ occurred. The physical exami- nation showed a deterioration in general functioning and upper quadrant hemianopsia but no signs of focal CNS damage and gait problems. In the angio-CT scan (Fig. 2), no vascular malformation was visualised; therefore, the patient did not qualify for surgery.
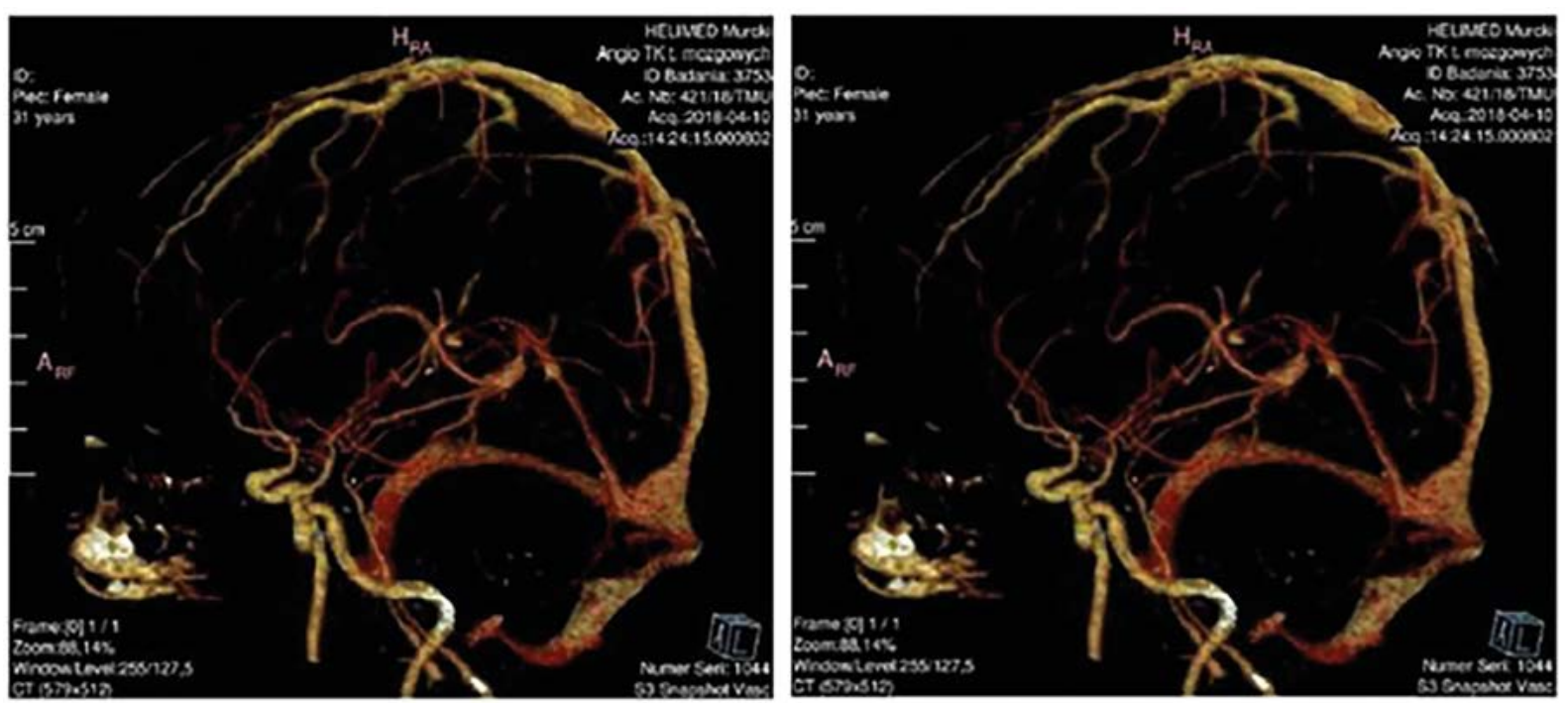

Figure 2. Angio-CT scan showed no vascular malformations.

Intensive anti-oedema and anti-haemorrhagic treatment were administered to speed up the absorption of the haematoma. Subsequent head CT scans revealed partial hemolysis of the haemorrhagic area (Fig. 3). During hospitalisation, which lasted for 23 days, from April 10 to May 2,2018 , the patient was stable and subsequently discharged in good condition. The subject rema- ined under medical care and had an MRI of the head ordered every six months. Hypersensitivity to smell, hearing and sight (left) were remnants of the stroke. Often headache and dizziness occurred, especially during weather changes. The patient followed the doctors' recommendations to exercise under the supervision of a physiotherapist, rest and try not to overexert themselves. 

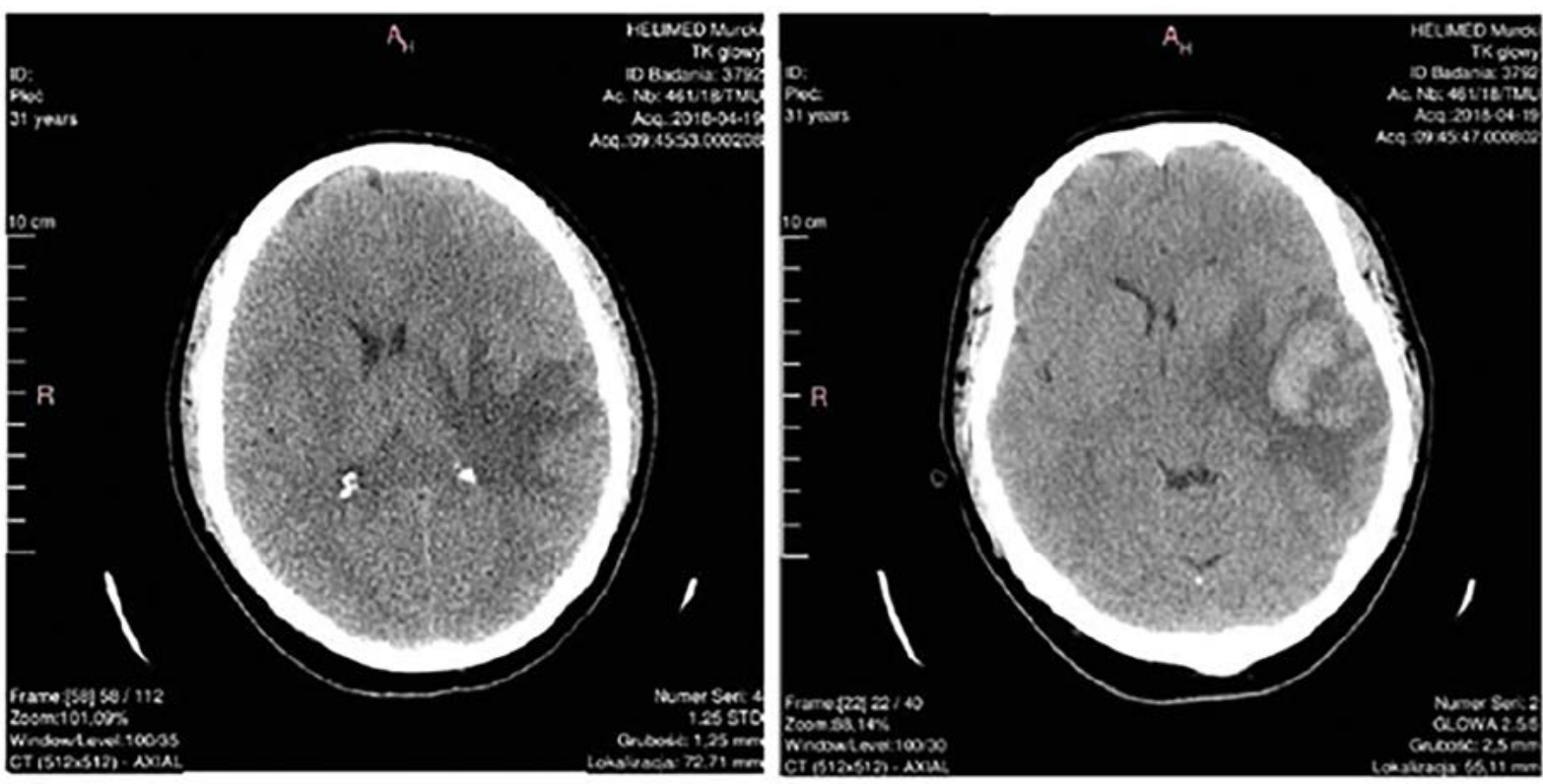

Figure 3. CT scan of the head revealed partial hemolysis of the haemorrhagic area.

Functional ability was assessed three times: at 8 days after leaving the hospital (23 days from the diagnosed stroke), 6 months and 1 year after hospital stay. The Barthel Index (BI), Berg balance scale (BBS) and Tandem Pivot Test (TPT) $\left(180^{\circ}\right.$ rotation test) were performed. In the last physiotherapeutic evaluation, the patient achieved ADL independence according to the assessment of independence in everyday activities.

The BI is the most useful tool for assessing individual effects in ADL [12]. The BI consists of 10 variables describing ADL and mobility, with a higher number reflecting a more remarkable ability to function independently following hospital discharge. The maximum number of points that can be obtained is 100 , which corresponds to an independent patient. The patient case report was given the following item scores: 70, 100 and 100 points at eight days, six months and one year after the hospital stay, respectively.

The BBS is an examination of 14 activities related to maintaining body balance [13]. These activities concern changes in position and maintaining balance in sitting and standing positions. There are 4 points for each task, and a total score of 41-56 points means an independent patient.
At eight days, six months and a year after hospital discharge, the case report patient obtained 31, 47 and 55 points, respectively.

The TPT $\left(180^{\circ}\right.$ rotation test) was used to evaluate the ability to maintain static body balance [14]. The patient's task is to rise onto their toes, turn $180^{\circ}$ without losing balance and place their feet on a line, keeping the wrong position (i.e., again feet one by one). Zero points are awarded when the patient needs help and assistance, and five points mean that the patient has no problem with a $180^{\circ}$ rotation performed in a coordinated manner and with maintaining post-rotation static body balance. It is acceptable to keep the feet a short distance apart after the turn [6]. At eight days, half a year and one year after the hospital stay, the case report patient obtained TPT scores of 3, 5 and 5 points, respectively. Three months after leaving the hospital, no abnormalities were found in the Mini-Mental Test cognitive functioning examination. The last angio-CT scan, dated July 14,2019 , showed no vascular malformations in the cerebral arteries but a visible scar caused by the intracerebral haematoma in the left temporal region (Fig. 4). 

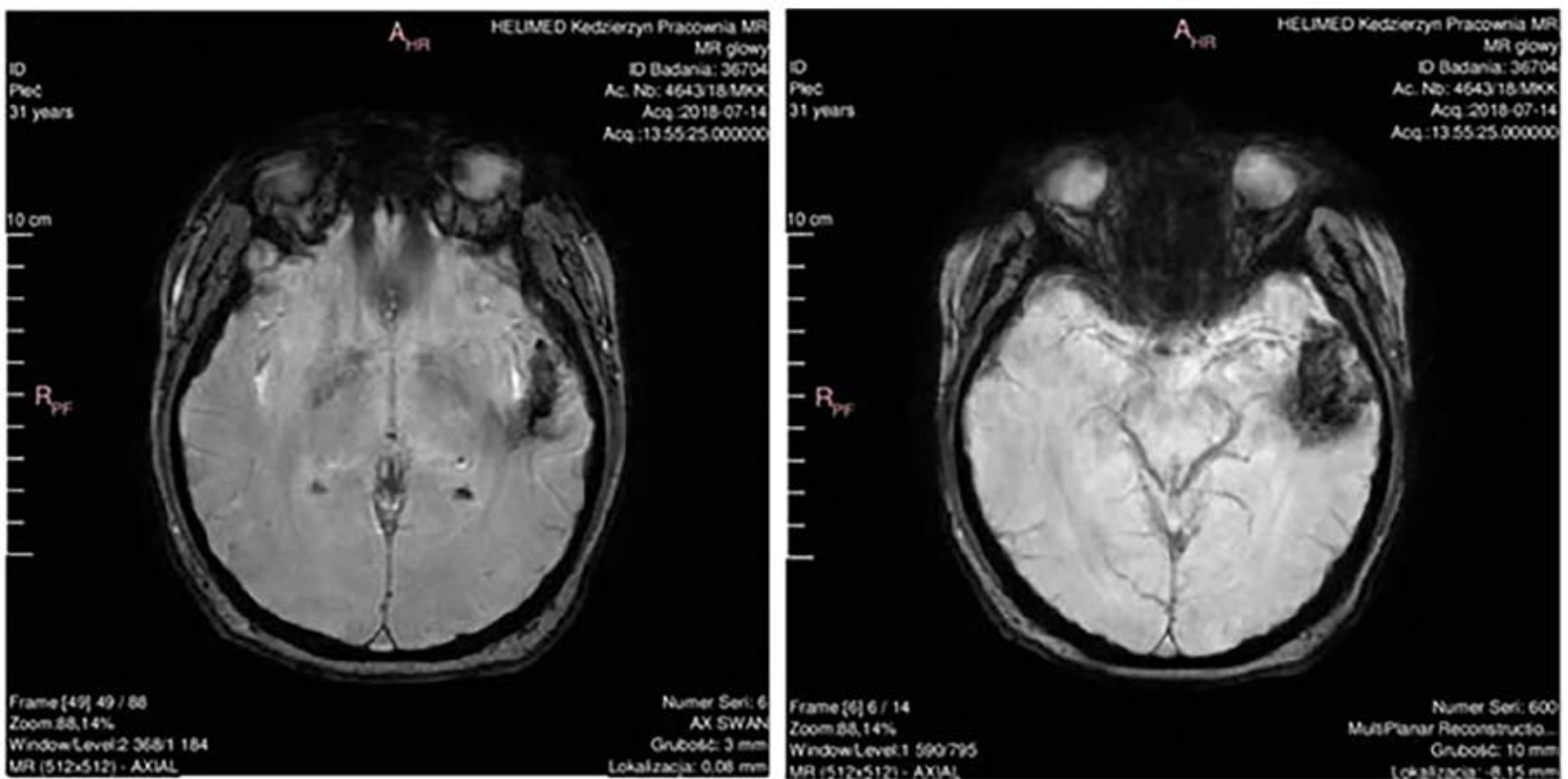

Figure 4. Angio-CT scan showed no vascular malformations but a visible scar caused by the intracerebral haematoma in the left temporal region.

General physical exercises under the supervision of a physiotherapist were prescribed after the hospital discharge. The programme began with a warm-up (cardio exercises) and included upper, lower and core exercises conducted once a day, five days a week, for three months.

The exercises in months one and two were to maintain the full range of motion of the joints and improve coordination and balance. In month three, muscle strengthening exercises were also added. A detailed description of the administered exercises is presented in Table 1. Later, the patient had no neurological symptoms and no ADL limitations; thus, no further rehabilitation was ordered.

\section{Discussion}

Cerebral strokes in young adults are rare, often difficult to diagnose [15] and a challenge to the health care system [16]. According to medical data, the overall stroke incidence in developed countries has been declining; however, there is evidence that the incidence of stroke among young people is increasing [17]. Moreover, the incidence of any stroke in young adults increases with age. In patients over 35 years of age, the incidence of any stroke is higher in women than men aged $18-44$ years, has increased by $23 \%$ in the last decade and is comparable for women and men [18]. Recent publications have reported that younger stroke patients have an increased risk of death compared with the general population, and stroke in the young has a disproportionately significant economic impact by leaving patients disabled before their most productive years [19, 20]. The potential causes of nontraumatic haemorrhagic stroke in young adults are many and require further studies [21]. The etiologic spectrum of stroke in the younger population may be wider than in older individuals and includes vascular malformations [22], hypertension, bacterial endocarditis, collagen vascular diseases, tumours, eclampsia, blood dyscrasias [23], smoking, alcohol use [24] and drug use [25], although a detailed discussion of potential causes is still needed [26].

Oral contraceptives also play a minor role in the risk of stroke in the young population when paired with other factors [27]. Other authors have emphasised that stress may be the leading cause of stroke, promoting unhealthy habits and lifestyles, such as smoking, poor treatment adherence, poor eating habits and low physical activity [28, 
Table 1. A detailed description of administered physical exercises.

\begin{tabular}{|c|c|c|c|}
\hline \multicolumn{4}{|c|}{ Month 1-2 } \\
\hline Description & Sets & Repetitions/Duration & Aim \\
\hline \multicolumn{3}{|c|}{ Cardio } & \multirow{14}{*}{$\begin{array}{l}\text { Maintaining full ROM } \\
\text { of the joints, improve } \\
\text { coordination and balance }\end{array}$} \\
\hline Jogging in place & - & For 5 min & \\
\hline Jumping jacks & 3 & 20 & \\
\hline \multicolumn{3}{|c|}{ Lower Body } & \\
\hline Squats & 3 & 20 & \\
\hline Gluteus bridge & 3 & 20 & \\
\hline \multicolumn{3}{|c|}{ Upper Body } & \\
\hline Standing arm circles & 3 & 20 each side & \\
\hline Wrist circles & 3 & 20 each side & \\
\hline Back extensions & 3 & 20 & \\
\hline Bottom to heels stretch & - & For $60 \mathrm{sec}$ & \\
\hline \multicolumn{3}{|c|}{ Core } & \\
\hline Plank & - & For $60 \mathrm{sec}$ & \\
\hline Raised leg circles & - & For $60 \mathrm{sec}$ & \\
\hline \multicolumn{4}{|c|}{ Month 3} \\
\hline Description & Sets & Repetitions/Duration & Aim \\
\hline \multicolumn{3}{|c|}{ Cardio } & \multirow{15}{*}{$\begin{array}{l}\text { Maintaining full ROM } \\
\text { of the joints, improve } \\
\text { coordination, balance } \\
\text { and improving muscle } \\
\text { strength }\end{array}$} \\
\hline Jumping rope & - & For 5 minutes & \\
\hline Jumping squats & 3 & 20 & \\
\hline & er Boc & & \\
\hline Wall-sit & 3 & For $60 \mathrm{sec}$ & \\
\hline Calf raises & 3 & 20 & \\
\hline Opposite arm and leg raise & 3 & 20 each side & \\
\hline \multicolumn{3}{|c|}{ Upper Body } & \\
\hline Door push-up & 3 & 20 & \\
\hline Superman row & 3 & 20 & \\
\hline Pike press & 3 & 20 & \\
\hline Back flexion stretch & - & For $60 \mathrm{sec}$ & \\
\hline \multicolumn{3}{|c|}{ Core } & \\
\hline Side plank & 3 & For 60 sec each side & \\
\hline Mountain climber & - & For $60 \mathrm{sec}$ & \\
\hline
\end{tabular}


29]. Psychological intervention programmes that target how to deal with stress lower the risk of another stroke.

The rehabilitation of young stroke patients is often associated with various social problems (e.g., child care responsibilities issues, marital disputes and unemployment), which are very important in this age group [27, 30]. Young stroke patients have a strong desire to fully return to society, but only a few studies have been conducted on their rehabilitation programmes [31, 32]. In rehabilitation, new technologies are used more and more often in addition to standard rehabilitation exercises and special physiotherapy methods. Virtual reality (VR) games and exergames are increasingly being used, especially with the help of gesture- and motion-sensing devices in post-stroke rehabilitation [33].

Li et al. analysed clinical data of young, middle-aged and older stroke patients in China [32]. Haemorrhagic stroke (59.6\%) was the primary stroke type found in the young group, while ischemic stroke $(60.0 \%)$ was mostly detected in the middle-aged and older group. Compared with older stroke patients, the incidence of hyperhomocysteinemia in younger patients was higher, whereas the incidences of chronic diseases, such as heart disease, hypertension and diabetes, were lower. The main risk factors observed in the young stroke patients were chronic diseases (hypertension, heart disease, hyperlipidemia, hyperhomocysteinemia, diabetes), improper lifestyle (drinking, smoking) and previous history of stroke. The most accepted rehabilitation programme consisted of regular physiotherapy, speech therapy, occupational therapy, moxibustion and acupuncture. The degree of disability and functional status improved significantly in young stroke patients following professional rehabilitation, and the BI increased at discharge. Six months after discharge, the degree of life satisfaction (such as friendship) improved, although occupational and economic satisfaction declined. No changes were observed in family life satisfaction.

\section{Limitations of the study}

The present study has several limitations. First, we present a case report of one subject without control and a comparison group. Furthermore, no reliable statistics and no objective evaluation of the therapeutic progress were presented. The efficacy of the prescribed physiotherapy exercise programme should be confirmed in high-quality therapeutic experiments, including control groups.

\section{Summary}

In this case report, a CT scan of the head of a 31-year-old woman revealed a haemorrhagic area in the left MCA territory, which is a prognostically alarming symptom if it occurs up to six hours after the stroke incident. In this case, almost two weeks passed from the first uncommon stroke symptoms to the proper medical treatment. Therefore, early assessment of stroke and its potential risk factors and prompt treatment and rehabilitation are essential to minimise post-stroke neurological complications. Despite the rare occurrence of stroke in young adults and the relative rareness of stroke compared with stroke mimics, increased awareness and the education of the medical staff and patients about the severity of stroke in the young and suggested physiotherapy exercise programmes offer a chance for proper medical and rehabilitation treatment and faster recovery for patients. 


\section{References}

1. Prusiński A. Neurologia praktyczna. Wydawnictwo Lekarkie PZWL. Warszawa 2007.

2. Podemski R. Kompendium neurologii. Wydanie II. Gdańsk 2011.

3. Singhal AB, Biller J, Elkind MS, et al. Recognition and management of stroke in young adults and adolescents. Neurology 2013; 81 (12): 1089-1097.

4. Opara J. Klinimetria w udarach mózgu. Wydawnictwo AWF. Katowice 2010.

5. Amstrong CL, Morrow L. Neuropsychologia medyczna. 1 tom. Wydawnictwo Lekarkie PZWL. Warszawa 2014.

6. Lizak A, Michalak K, Śliwka A, Wierciak A. Dokumentacja fizjoterapeutyczna zgodna z wytycznymi ICF. Wydawnictwo Reha Plus. Kraków 2013.

7. Mazur R, Książkiewicz B, Nyka. MW. Udar mózgu w praktyce lekarskiej. Wydawnictwo Via Medica, Gdańsk 2010

8. Majersik JJ. Inherited and uncommon causes of stroke. Continuum (Minneap Minn) 2017; 23 (1): 211237. doi: $10.1212 / C O N .0000000000000432$.

9. Kittner SJ, Stern BJ, Wozniak M. et al. Cerebral infarction in young adults: the Baltimore-Washington Cooperative Young Stroke Study. Neurology. 1998; 50 (4): 890-894. doi: 10.1212/wnl.50.4.890.

10. Ferro JM, Massaro AR, Mas JL. Aetiological diagnosis of ischaemic stroke in young adults. Lancet Neurol. 2010; 9 (11): 1085-1096. doi: 10.1016/S14744422(10)70251-9.

11. Ji R, Schwamm LH, Pervez MA, Singhal AB. Ischemic stroke and transient ischemic attack in young adults: risk factors, diagnostic yield, neuroimaging, and thrombolysis. JAMA Neurol. 2013; 70 (1): 51-57. doi: 10.1001/jamaneurol.2013.575.

12. Musa KI, Keegan TJ. The change of Barthel Index scores from the time of discharge until 3-month post-discharge among acute stroke patients in Malaysia: A random intercept model. PLoS One. 2018; 13 (12): e0208594. doi:10.1371/journal.pone.0208594.

13. Szostek-Rogula S, Zamysłowska-Szmytke E. Przegląd skal i testów dla oceny czynnościowej pacjenta $\mathrm{z}$ zawrotami głowy i zaburzeniami równowagi. Otorynolaryngologia 2015, 14 (3): 141-149.
14. Middleton A, Fritz SL. Assessment of gait, balance, and mobility in older adults: considerations for clinicians. Curr Transl Geriatr and Exp Gerontol Rep. 2013; 2: 205-214. https://doi.org/10.1007/s13670013-0057-2.

15. Bevan H, Sharma K, Bradley W. Stroke in young adults. Stroke 1990; 21 (3): 382-386. doi: 10.1161/01. str.21.3.382.

16. Ellis C. Stroke in young adults. Brief report. Disabil Health J. 2010; 3 (3): 222-224. https://doi.org/10.1016/j.dhjo.2010.01.001

17. Aigner A, Grittner U, Rolfs A, Norrving B, Siegerink B, Busch MA. Contribution of Established Stroke Risk Factors to the Burden of Stroke in Young Adults. Stroke 2017; 48 (7): 1744-1751. doi: 10.1161/STROKEAHA.117.016599.

18. Sultan S, Elkind MS. The growing problem of stroke among young adults. Curr Cardiol Rep. 2013; 15 (12): 421. doi: 10.1007/s11886-013-0421-z.

19. Ekker MS, Verhoeven JI, Vaartjes I, van Nieuwenhuizen KM, Klijn CJM, de Leeuw FE. Stroke incidence in young adults according to age, subtype, sex, and time trends. Neurology. 2019; 92 (21): e2444-e2454. doi: 10.1212/WNL.0000000000007533.

20. Smajlović D. Strokes in young adults: epidemiology and prevention. Vasc Health Risk Manag 2015; 24; 11: 157-164. doi: 10.2147/VHRM.S53203.

21. Tatlisumak T, Cucchiara B, Kuroda S, Kasner SE, Putaala J. Nontraumatic intracerebral haemorrhage in young adults. Nat Rev Neurol. 2018; 14 (4): 237250. doi: $10.1038 /$ nrneurol.2018.17.

22. Kuruvilla A, Bhattacharya P, Rajamani K, Chaturvedi S. Factors associated with misdiagnosis of acute stroke in young adults. J Stroke Cerebrovasc Dis. 2011; 20 (6): 523-527. doi: 10.1016/j.jstrokecerebrovasdis.2010.03.005.

23. McEvoy AW, Kitchen ND, Thomas DG. Lesson of the week: intracerebral haemorrhage in young adults: the emerging importance of drug misuse. BMJ 2000; 320 (7245): 1322-1324. doi: 10.1136/ bmj.320.7245.1322. 
24. Koivunen RJ, Satopää J, Meretoja A, Strbian D, Haapaniemi $\mathrm{E}$, Niemelä $\mathrm{M}$, et al. Incidence, risk factors, etiology, severity and short-term outcome of non-traumatic intracerebral hemorrhage in young adults. Eur J Neurol. 2015; 22 (1): 123-132. doi: 10.1111/ ene.12543.

25. McEvoy AW, Kitchen ND, Thomas DG. Intracerebral haemorrhage and drug abuse in young adults. Br J Neurosurg. 2000; 14 (5): 449-454. doi: $10.1080 / 02688690050175247$.

26. Ruíz-Sandoval JL, Cantú C, Barinagarrementeria $\mathrm{F}$. Intracerebral hemorrhage in young people: analysis of risk factors, location, causes, and prognosis. Stroke 1999; 30 (3): 537-541. doi: 10.1161/01. str.30.3.537.

27. Teasell RW, McRae MP, Finestone HM. Social issues in the rehabilitation of younger stroke patients. Arch Phys Med Rehabil. 2000; 81 (2): 205-209. doi: 10.1016/s0003-9993(00)90142-4.

28. González-Gómez FJ, Pérez-Torre P, DeFelipe A, Vera R, Matute C, Cruz-Culebras A, et al. Stroke in young adults: Incidence rate, risk factors, treatment and prognosis. Rev Clin Esp. 2016; 216 (7): 345351. English, Spanish. doi: 10.1016/j.rce.2016.05.008.

29. Olsson EMG, Norlund F, Pingel R, Burell G, Gulliksson M, Larsson A, et al. The effect of group-based cognitive behavioral therapy on inflammatory biomarkers in patients with coronary heart disease-results from the SUPRIM-trial. Ups J Med Sci. 2018; 123 (3): 167-173. doi: 10.1080/03009734.2018.1 490829.
30. Cotoi A, Batey C, Hussein N, Janzen S, Teasell R. Rehabilitation of Younger Patients Post Stroke In: The Evidence-Based Review of Stroke Rehabilitation, EBRSR; 2018: 1-53. [on-line at: http://www.ebrsr. $\mathrm{com} /]$.

31. Engbers LH, Vollenbroek-Hutten MM, van Harten WH. A comparison of patient characteristics and rehabilitation treatment content of chronic low back pain (CLBP) and stroke patients across six European countries. Health Policy 2005; 71 (3): 359373. doi: 10.1016/j.healthpol.2004.03.006.

32. Li CJ, Du XX, Yang K, et al. Effects of professional rehabilitation training on the recovery of neurological function in young stroke patients. Neural Regen Res. 2016; 11 (11): 1766-1772. doi:10.4103/16735374.194746.

33. Trombetta M, Bazzanello Henrique PP, Brum MR, Colussi EL, De Marchi ACB, Rieder R. Motion Rehab AVE 3D: A VR-based exergame for post-stroke rehabilitation. Comput Methods Programs Biomed. 2017; 151: 15-20. doi: 10.1016/j.cmpb.2017.08.008. 